\title{
When a New Platform Enters a Market, What Is the Impact on Incumbents? Andreas J. Steur
}

\author{
(6 Platforms beat pipelines because platforms unlock new \\ sources of value creation and supply. \\ G. G. Parker, M. W. Van Alstyne, and S. P. Choudary \\ In Platform Revolution (2016)
}

\begin{abstract}
Digital platforms enable new forms of business models with the potential to disrupt and transform many industries. However, the impact of a platform's market entry on incumbents has not been taken into account. In this article, our objective is to provide evidence of the impact that a platform's market entry could have on incumbents. We proposed several hypotheses based on a literature review and then evaluated them using a large dataset from the taxi industry in New York City. Our analysis showed several changes after a platform's market entry. In contrast to previous understanding, the results indicate that the winner-takes-it-all-effect does not generally apply to the competition between new platforms and incumbents. Regarding the date of changes following a platform's market entry, we observed a chicken-or-egg problem in the competition between a platform and incumbents. Consequently, our results indicate that incumbents have at least one year to react to the market entry and to make adjustments.
\end{abstract}

\section{Introduction}

Increasingly, digital platforms are being introduced into existing markets to complement product customization, digitization, the embedding of software into existing business activities, the Internet of Things, and the ubiquitous availability of the Internet (Tiwana, 2014). Indeed, most companies with a large market capitalization, such as Apple and Alphabet, run platform business models (Parker et al., 2016). These business models are often eliminating existing market entry barriers and, due to unleashing network effects, are changing the existing business environment as well as the competition in these markets as a result of rapid growth (Choudary, 2015; Tiwana, 2014). Some impacts of a platform's market entry on established companies are known based on case studies. However, there is no general understanding of these effects in current literature and practice.

Currently, there is no generally accepted definition of digital platforms. One definition characterizes platforms as "products and services that bring together groups of users in two-sided networks" (Eisenmann et al., 2006). In contrast, another definition focuses on the interactions of platforms: "a platform is a business based on enabling value-creating interactions between external producers and consumers" (Parker et al., 2016). Platforms are based on the idea of an ecosystem in which the participants of individual market sides can interact (Gawer \& Cusumano, 2014; Tiwana, 2014, Van Alstyne et al., 2016). Platforms have to be differentiated from pipelines and business ecosystems (Adner, 2017; Muegge, 2011; Van Alstyne et al., 2016). A pipeline controls and optimizes its internal resources and is characterized by a material flow towards the customer (Van Alstyne et al., 2016). In contrast, business ecosystems are the organization of external actors (Muegge, 2013). These actors interact and have a defined position and functions within the ecosystem (Adner, 2017). Platforms are defined by the organization of things (Muegge, 2013) that are characterized by mutuality, interaction via the digital infrastructure, network effects, and the coordination of external resources (Armstrong, 2006; Brousseau \& Penard, 2007; Rochet \& Tirole, 2003; Tiwana, 2014; Van Alstyne et al., 2016) 


\section{When a New Platform Enters a Market, What Is the Impact on Incumbents?}

Andreas J. Steur

So far, the literature has focused on the above-mentioned characteristics. The impact of a platform's market entry on incumbents, which are companies established in the market without any platform-based business models, has not been taken into account. In addition, it is well known that network effects do not occur until reaching critical mass, but it is not clear whether the impacts within the competition are delayed. Here, we aim to develop an understanding of the platform business model and its environment by asking two questions: What are the effects of a platform's market entry on incumbents? Do these effects occur immediately or with a time delay?

The article proceeds as follows. First, we examine the literature to identify what is known about the impacts of a platform's market entry on incumbents. Our literature review focuses on selected cases, its effects on incumbents after a platform's market entry, and explanatory approaches from the field of industrial economics. Based on the results of the literature review, we deduce hypotheses. Then, we describe the analysis methods to identify changes following a platform's market entry. Finally, we verify the hypotheses and discuss the results to analyze the impacts of a platform's market entry on incumbents.

\section{Impacts of a Platform's Market Entry on Incumbents}

A platform's market entry is associated with many effects on the incumbents. The winner-takes-it-all effect is one impact that is discussed in the literature regarding competition between platforms. This effect implies that, due to unleashed network effects acting over time, only one platform survives and the other competing platforms are pushed out of the market. Consequently, the surviving platform occupies a position similar to a monopoly. This type of dominance is commonly observed in markets where suppliers and customers each only tend to participate in one platform - so-called single-home markets. However, first-mover advantage is not of great importance in achieving this market position (Eisenmann et al., 2006; Sun \& Tse, 2007). This displacement only refers to the competition between platforms, but it can be observed in competition between a platform and non-platform incumbents. For example, following Amazon's (amazon.com) and eBay's (ebay.com) market entry, non-platform incumbents were displaced by the platform-based newcomers (Hotz \& Fost, 2017; Täuscher et al., 2017). Due to network effects and the coordination of external resources, plat- forms have advantages in competition with linear valuecreation models, which are also called "pipes". Therefore, we assume that, over the long term, the platform will succeed in the competition between platforms and non-platform incumbents. Consequently, we introduce our first hypothesis.

\section{Hypothesis 1: The winner-takes-it-all effect occurs in the competition between a new platform and in- cumbents.}

To identify further impacts, we use models from industrial economics. Therefore, we consider basic models and state strategic possibilities to react to after a platform's market entry. Before the platform enters the market, the incumbent has a market position similar to that of a monopoly and occupies the entire market. In this case, the price set by the incumbent is higher than its variable costs. When the platform enters the market, the competition changes. In general, a platform does not have a capacity restriction. Therefore, we assume that a platform and incumbents are in a price war. For reasons of practicability, we expect that, after a platform's market entry, there will be two symmetric companies. This implies that both competitors have identical variable costs $c$ and fixed costs $F$. The cost structure, which depends on the sales volume $q$, can be approximated with the following function: $K(q)=c \cdot q-F$. Both companies choose an equilibrium price equal to the variable costs and achieve losses equal to the fixed costs (Bertrand, 1883; Tirole, 1999). This equilibrium price is lower than the price of the basic model. The lower price can be seen in the example of the market entry of Craigslist (craigslist.org), an online classified advertisement platform that competes with newspapers. The price of newspaper advertisements declined following the market entry (Seamans \& Zhu, 2010). Consequently, we introduce our second hypothesis.

\section{Hypothesis 2: A platform's market entry causes a price decrease among incumbents.}

Considering the competition of two symmetrical companies, the platform and the incumbent share market demand equally. Before the platform's market entry, there was a monopoly and the incumbent satisfied the entire market demand. Therefore, the incumbent's sales volume decreases after a platform's market entry (Tirole, 1999). This effect was recognizable after Uber's (uber.com) ride-sharing market entry in Chicago, where the taxi industry (i.e., the non-platform incumbents) suffered a decrease in trip volume following the platform's market 


\title{
When a New Platform Enters a Market, What Is the Impact on Incumbents?
}

\author{
Andreas J. Steur
}

entry (Wallsten, 2015). Similarly, a decrease in sales volume occurred in the competition between Craigslist and newspapers (Seamans \& Zhu, 2010). As a consequence of the described effect, we introduce the next hypothesis.

\section{Hypothesis 3: A platform's market entry causes a decrease in incumbents' sales volume.}

A platform's market entry changes the situation from a monopoly to competition between two symmetrical companies. Due to lower price and sales volume, the revenue and profit of the incumbent decrease (Tirole, 1999). Airbnb's (airbnb.com) market entry in Texas is an example of this effect: the revenue of hotel businesses declined following the market entry of Airbnb's online marketplace and hospitality service (Oskam \& Boswijk, 2016; Zervas, 2017). Consequently, we introduce our fourth hypothesis.

\section{Hypothesis 4: A platform's market entry causes a decrease in incumbents' revenue.}

Eventually, the competition between a platform and an incumbent will no longer fit with the model of two symmetric companies. Due to the coordination of external resources and the unleashing of network effects, a platform has almost no variable costs (Evans \& Schmalensee, 2016; Van Alstyne et al., 2016). Consequently, the competition would be better approximated to a model of two asymmetric companies. The only difference between this model and the model of two symmetrical companies is the diverging variable costs. In this kind of competition, a platform sets a price higher than its variable costs and lower than the incumbent's variable costs. It is not profitable for the incumbent to set a price lower than its own variable costs, as the incumbent's losses would be higher with each unit sold. In the equilibrium, the platform serves the entire market, while the incumbent no longer sells anything. As a result, the platform has a higher equilibrium sales volume and a higher profit, while the incumbent continues to make losses in terms of fixed costs (Tirole, 1999). These changes support the effects introduced in hypotheses 3 and 4 .

In addition to discussed models, incumbents can react by choosing the strategies of cost leadership or differentiation (Porter, 1998). If an incumbent reacts by choosing cost leadership, it will reduce their variable costs. On the basis of competition between symmetric companies, the incumbent would try to achieve lower variable costs through higher quantities. To achieve this, the incumbent would set lower prices than in the basic model and try to satisfy the entire market. This type of competition is comparable to the model described between two asymmetric companies. In this case, however, the incumbent has lower variable costs (Tirole, 1999). This strategic choice supports hypothesis 2 . Another strategic possibility for incumbents is differentiation, which can be vertical or horizontal (Shy, 2010). Horizontal differentiation implies divergent features or locations. The hotelling model is an approach from industrial economics declaring horizontal differentiation. In the case of differentiation, both companies choose a higher equilibrium price and gain higher profit (Hotelling, 1929; Tirole, 1999). Based on a positive effect of horizontal differentiation on incumbent's profit, we introduce hypothesis 5 .

Hypothesis 5: A platform's market entry causes horizontal differentiation as a strategic reaction.

Within vertical differentiation, incumbents react by choosing higher product or service quality. Therefore, incumbents can set higher prices. The hotelling model can be used with adjustments for vertical differentiation. This model also illustrates higher equilibrium prices and higher profits (Shy, 2010; Tirole, 1999). Due to the positive effect of the choice of vertical differentiation, we introduce hypothesis 6.

\section{Hypothesis 6: A platform's market entry causes ver- tical differentiation as a strategic reaction.}

Network effects are propagated as an essential advantage of platforms. However, these effects only occur after reaching a critical mass or tipping point, which means that this is a chicken-or-egg-problem (Chaillaud \& Jullien, 2003; Evans \& Schmalensee, 2016; Tiwana, 2014). Since there are no network effects within the incumbent's business model, they can represent a kind of competitive advantage of the platform. Due to the influence of the network effects after reaching critical mass, the changes caused by the platform's market entry on incumbents only appear after successful scaling. Therefore, there is a time delay in the occurrence of the changes, which leads us to introduce hypothesis 7.

\section{Hypothesis 7: The impacts of a platform's market entry on incumbents occur with a time delay.}

Summarizing, there are several effects following a platform's market entry. In the next section, we describe the methodology for testing our hypotheses using the example of the taxi business in New York City. 


\section{When a New Platform Enters a Market, What Is the Impact on Incumbents?}

\section{Andreas J. Steur}

\section{Method}

After developing hypotheses regarding the expected changes caused by a platform's market entry, we now illustrate the data preparation and analysis method.

We analyze the taxi market in New York City for changes after Uber's market entry. For the empirical analysis, we use an open dataset of yellow and green cabs from January 2009 to June 2016, which is provided by the New York City Taxi and Limousine Commission. The dataset includes a population of approximately 1.3 billion taxi trips with a database size of 210 gigabytes. Consequently, we developed a Java program to aggregate and analyze the dataset. The program aggregates the values of a single trip on a daily basis. For a detailed analysis and for more accurate results, the pickup locations of single trips are assigned to district boundaries. Polygons are used to approximate these boundaries. For more information about the trips in the downtown area, we divide Manhattan into the North of Manhattan and downtown. Our partitioning is similar to that of the taxi and limousine commission between yellow and green cabs. To the West, the border runs along the 110th street North of Central Park, to the East along the 96th street (TLC, 2017). In addition to the individual districts, we consider both airports. The borders of the districts are illustrated in Figure 1.

The empirical analysis is performed by means of a time series analysis. With regard to our analysis, we ignore seasonal and cyclical trends. Therefore, the considered model of time series analysis is only depending on temporal changes. We verify changes after Uber's market entry in New York City and the time of change utilizing structural breakage test. If there is any impact following Uber's market entry into the individual endogenous variables, there should be a structural break since the market entry. Therefore, two different splines within the same model with different coefficients would fit the actual development better than a regression line (Hackl, 2013). There are many statistical tests for structural breaks. Due to the propagated chicken-or-egg problem, changes can occur with a time delay (Caillaud

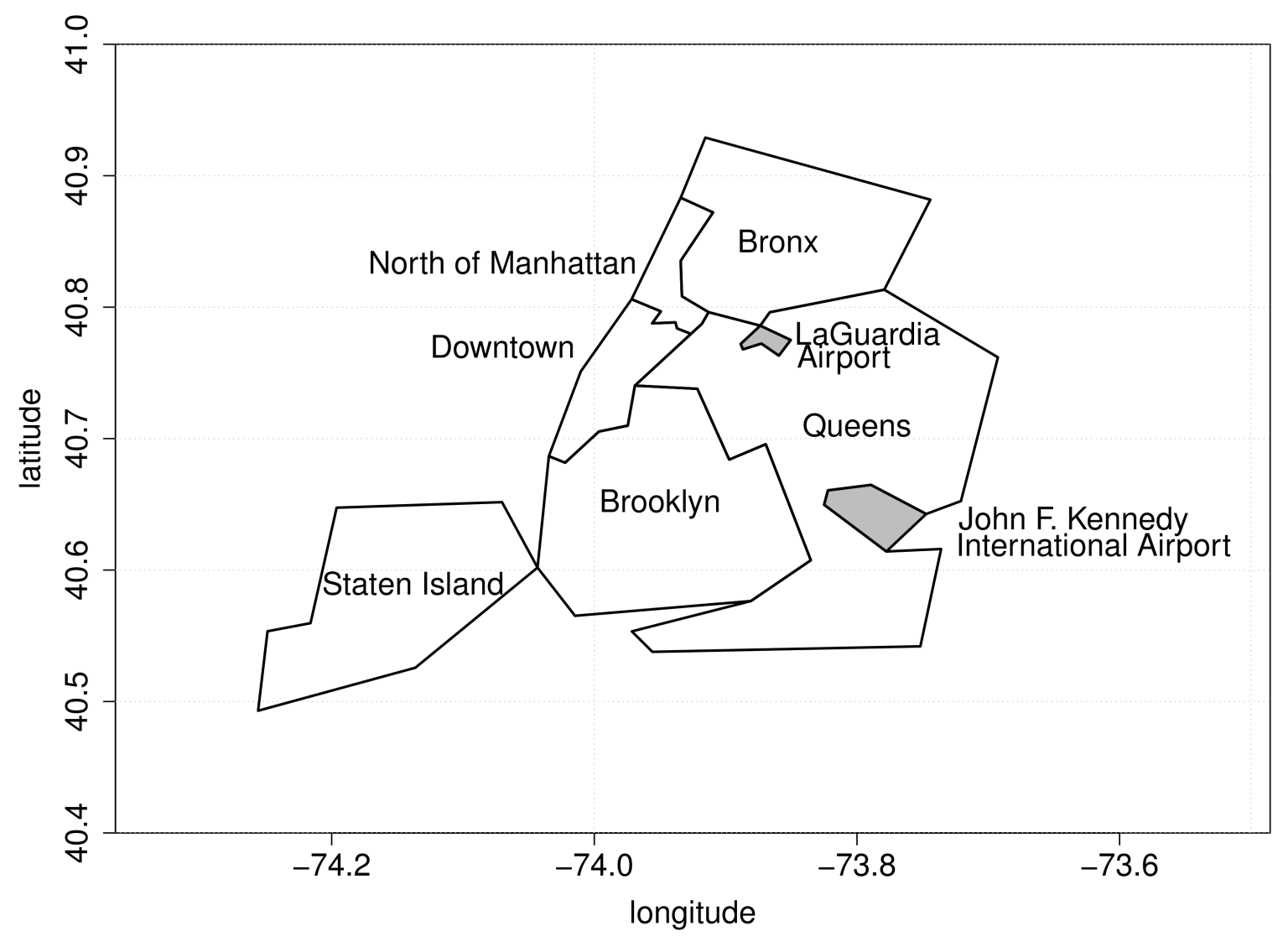

Figure 1. Polygons of New York City's districts 


\title{
When a New Platform Enters a Market, What Is the Impact on Incumbents?
}

\author{
Andreas J. Steur
}

\& Jullien, 2003; Tiwana 2014). Due to an unknown change point, we use a method based on Bai (1994) to identify the optimal breakpoint. The method is a special case for determining unknown structural breaks and a test procedure such as the Quandt-Andrews test (Bai, 1994), which is used for a limited time interval of $15 \%$ to $85 \%$ of the entire observation period (Andrews, 1993). In addition, we use the Chow test to check whether the true values can be better approximated using two linear regressions than with one regression line at the identified breakpoints (Chow, 1960). Following the structural breakage tests, we identify the two splines and address the changes between both splines. The changes are assessed as follows. If there is a significant positive or negative shift of the spline after the structural break, the change is evaluated according to the shift direction. In addition, we consider the gradients of the splines. If the gradient of the splines changes from a positive to a negative value or the gradient of the splines decreases significantly, there is a negative effect after the market entry. If the gradient of the splines changes from a negative to a positive value or the gradient of the splines increases significantly, there is a positive effect after the market entry.

Due to the data basis, the variables sales volume, horizontal and vertical differentiation cannot be extracted and analyzed directly. For the approximation, we use the following variables. The sales volume is tested by using the number of trips and the total distance. We approximate the vertical differentiation by using paid tips, thus the quality of the trip, the condition of the car, and the safety of the trip influence the paid tip. In order to investigate the horizontal differentiation, we examine all districts of New York City for changes in price, sales volume, and revenue. In order to examine the validity of the winner-takes-it-all effect, the results of hypotheses 2-6 are considered. If there are negative impacts on price, sales volume, and revenue, as well as no strategic reaction such as horizontal and vertical differentiation after a platform's market entry, the winner-takes-it-alleffect occurs in the competition between a platform and incumbents.

\section{Results}

In order to analyze the effects of a platform's market entry on incumbents, we carried out a structural breaks analysis in accordance with Bai (1994) and Chow (1960). In addition, we verified the date of structural breaks and the type of changes.
Within our analysis, we identified structural breaks for all variables. Using the Chow test, the null hypothesis at a significance level of $\alpha=0.001$ was rejected for all variables within all districts, so that a structural break exists at the identified breakpoints. Breakpoints of trips in John F. Kennedy International Airport and Staten Island, total distance in John F. Kennedy International Airport and LaGuardia Airport and trip distance in John F. Kennedy International Airport and LaGuardia Airport occurred before Uber's market entry. Using the described approach, there were positive effects on the price recognizable in downtown, LaGuardia Airport, and Staten Island. In the other districts, there were negative changes of the price following the structural breaks. Across the entire city, we observed positive effects on price. The analysis of the number of trips showed negative effects for downtown and La Guardia Airport, while there were positive changes after the market entry in the Bronx, Brooklyn, the north of Manhattan, and Queens. Regarding the total distance per day, there were negative effects for downtown. For all other districts, there were positive changes on the total distance. We saw negative effects for the number of trips and the total distance for the entire city. In Brooklyn, the Bronx, the north of Manhattan, Queens, and Staten Island, there were positive changes in revenue following the breakpoint. For trips starting in downtown and both airports, there were negative effects on revenue. The same applies to the entire city. In Brooklyn, the Bronx, the north of Manhattan, and Queens negative effects appeared on paid tip following the market entry. In downtown, Staten Island, and both airports, there were positive changes recognizable. For the entire city, there were positive effects on paid tips. With regard to single trip distance, we observed negative changes following the breakpoint. Table 1 summarizes the results of our analysis.

\section{Discussion}

Our analysis of prices after Uber's market entry showed obvious changes. For all districts, apart from the Bronx, there was a structural break at September 2012. In the Bronx, the breakpoint was observable one year later. Since September 2012, taxi drivers in New York City can charge a higher price to their passengers. The price of a single trip is fixed on several parameters such as the travelled distance and the duration of the trip. Therefore, the price changes indicated a change in those parameters. In general, an increase in price could be assumed. This increase took place after Uber's market 


\section{When a New Platform Enters a Market, What Is the Impact on Incumbents?}

\section{Andreas J. Steur}

Table 1. Overview of results

\begin{tabular}{|c|c|c|c|c|c|c|}
\hline & Price & Trips & Total Distance & Revenue & Paid Tip & Trip Distance \\
\hline Bronx & negative & positive & positive & positive & negative & negative \\
\hline Brooklyn & negative & positive & positive & positive & negative & negative \\
\hline Downtown & positive & negative & negative & negative & positive & negative \\
\hline JFK Int. Airport & negative & & & negative & positive & \\
\hline LaGuardia Airport & positive & negative & & negative & positive & \\
\hline North of Manhattan & negative & positive & positive & positive & negative & negative \\
\hline Queens & negative & positive & positive & positive & negative & negative \\
\hline Staten Island & positive & & positive & positive & positive & negative \\
\hline New York City & positive & negative & negative & negative & positive & negative \\
\hline
\end{tabular}

entry. Official reasons for the price increase were higher cost of living and increased gasoline prices (TLC, 2012). These might not be all the reasons for the price increase. Due to Uber's market entry, the competition in the transportation business could be harder. Consequently, the taxi and limousine commission decided to introduce higher prices. In summary, we identified decreases and increases of prices following Uber's market entry. Therefore, hypothesis 2, which implies a price decrease following a platform's market entry, was rejected.

Another propagated effect is a decrease in sales volume. To analyze this effect, we considered the number of trips per day and the total distance per day. Within the number of trips and the total distance, there were structural breaks for all districts. Breakpoints of the number of trips occurred before Uber entered into the market at John F. Kennedy International Airport and Staten Island. For trips starting from John F. Kennedy International Airport and LaGuardia Airport, the breakpoints of the total distance appeared before Uber's market entry. For all other districts, changes were obvious after more than after more than two years and seven months following Uber's market entry. In summary, there were positive, negative, and no changes of sales volume following Uber's market entry. Consequently, hypothesis 3 was rejected.
Regarding revenue, changes occurred between one year and four months and two years and ten months. Since there were negative changes in downtown and at both airports compared to positive changes in the other parts of the city and there were negative changes in turnover across the entire city, this indicates the importance of trips starting downtown. The dates of the structural breaks in the revenue of the trips departing from John F. Kennedy International Airports, LaGuardia Airports and downtown were the same as the dates of the price adjustment. The dates of the structural breaks in the revenue of the entire city and the districts of the Bronx, Brooklyn, the north of Manhattan, Queens, and Staten Island were the same as those of the changes of sales volume. This was not surprising, as revenue is based on the product of sales volume and price. Due to positive changes in most districts, hypothesis 4 was rejected.

Following a platform's market entry, vertical differentiation is a possible reaction by the incumbent. We used paid tips to approximate this potential effect. In the Bronx, changes were recognizable in November 2013, and in Staten Island, they occurred in May 2015. For all other districts, structural breaks appeared in September 2012. The breakpoints were similar to those points of the price change. This indicates that the paid tip was dependent on the regular price per trip. Thus, there 


\title{
When a New Platform Enters a Market, What Is the Impact on Incumbents?
}

\author{
Andreas J. Steur
}

were positive and negative changes as well as the positive effects depended on price changes, so hypothesis 5 was rejected.

Another strategic reaction could be horizontal differentiation, which we analyzed using the single trip distance and the previously examined variables. Within these variables, we paid attention to common differences between individual districts. The changes of the single trip distance of both airports were negative, but the structural breaks occurred in 2010 and 2011 - before Uber's market entry. In summary, there was a shorter trip distance after Uber's market entry. Next, we took a close look at the variables price, number of trips, total distance, revenue, and paid tips. For most variables, we identified different changes in two categories of districts. In the first category, nearly all variables showed positive effects, whereas they were negative in the second category. Components of the first category were Brooklyn, the Bronx, the north of Manhattan, and Queens. Both airports and downtown are components of the second category. The different categories, as well as the changes in trip distance, indicated a horizontal differentiation after the market entry. Therefore, hypothesis 6 was not rejected.

To verify whether the winner-takes-it-all effect applies to the competition between a platform and incumbents, we analyzed changes in the entire city and those in each district following Uber's market entry. For the entire city, there were mainly negative changes observable. This indicated that incumbents were pushed out of the market. With regard to the individual districts, there were positive and negative changes for the analyzed variables. In particular, the horizontal differentiation and the positive changes in the Bronx, Brooklyn, the north of Manhattan, and Queens showed that some drivers focused more on those areas. Therefore, these incumbents focused on a market niche. Due to the methodology, we could not generally determine whether the negative effects of the whole city were equivalent to a positive development of Uber. However, as the company has grown to $\$ 50$ billion USD in sales and distribution in more than 200 cities since its founding, it still points to this change (Parker et al., 2016). In summary, the winner-takes-it-all effect does not occur in the competition between a platform and incumbents in general, according to our results. Rather, incumbents are focusing on a market niche after a platform's market entry. Consequently, hypothesis 1 was rejected.
As a last effect, we considered the timing of changes, which are shown in Figure 2. The price changes varied between districts and variables and showed a range between almost one year and over four years following Uber's market entry. Price changes occurred one year and four months after the market entry. The breakpoints of the number of trips and the total distance were distributed approximately after two years and nine months. With regard to revenue, there was a higher variation in the timing of breakpoints. Some breakpoints occurred after approximately one year and four months (e.g., John F. Kennedy International Airport, Downtown, the north of Manhattan and Staten Island) and others occurred after approximately two years and nine months (e.g., the Bronx, Brooklyn, LaGuardia Airport, Queens, and the entire city). The breakpoints of paid tips occurred in almost all districts after one year and four months. Only the districts the Bronx (two years and six months) and Staten Island (more than four years) differ. The strongest variations of the breakpoints' timing exist in trip distance. The breakpoints occurred between almost one year (e.g., Brooklyn) and three years and six months (e.g., Downtown). The distribution of the breakpoints of the considered variables showed that the effects appeared with a time delay of almost one year. Consequently, there were also scaling problems after Uber's market entry. The scaling problem was solvable after reaching a critical mass. Thus, the platform grows independently (Chaillaud \& Jullien, 2003; Tiwana 2014). Once a critical mass is achieved, the impact on incumbents becomes apparent. In the case of the taxi market in New York City, the impacts occurred with a delay of more than one year. Consequently, the practical implication is that incumbents have at least one year to react following the platform's market entry. The incumbents also have options in terms of how they react. For example, their business model can be transferred to a platform or further legal changes could be effected. Therefore, hypothesis 7 was not rejected.

In summary, we examined several hypotheses, and the results are summarized in Table 2. Hypotheses relating to horizontal differentiation as a strategic reaction and a time delay of changes were not rejected. The winnertakes-it-all effect was not proven. Rather, due to the horizontal differentiation, a displacement took place in a niche. We could not prove the reduction of price, sales volume, turnover, and vertical differentiation as a strategic reaction. 


\section{When a New Platform Enters a Market, What Is the Impact on Incumbents?}

\section{Andreas J. Steur}

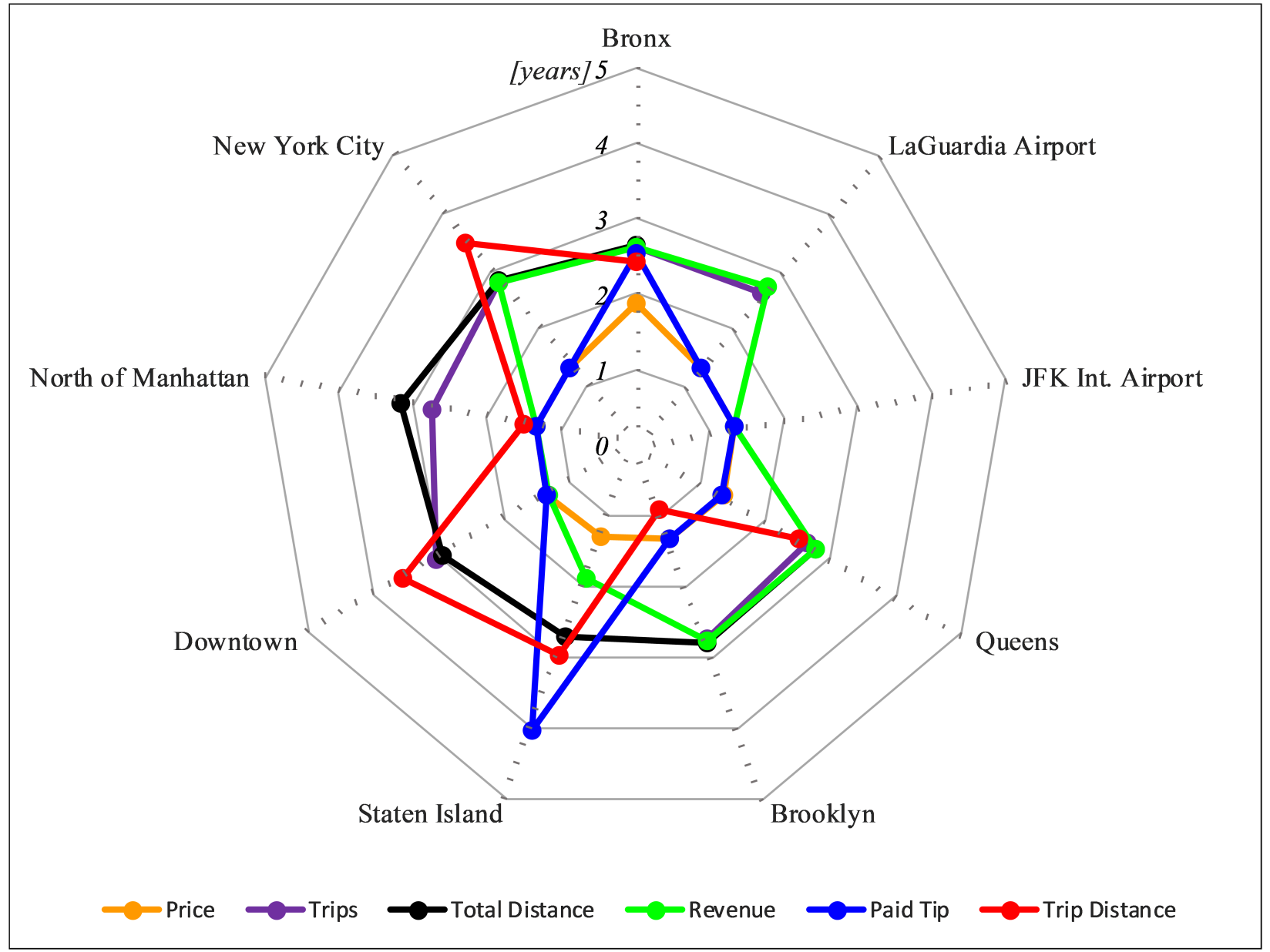

Figure 2. Number of days until breakpoints

Table 2. Measured impacts of a platform's market entry on incumbents

\begin{tabular}{cll}
\hline Hypothesis & Predicted Effect & Result \\
\hline H1 & Winner-takes-it-all & Rejected \\
\hline H2 & Price decrease & Rejected \\
\hline H3 & Decrease in sales volume & Rejected \\
\hline H4 & Decrease in revenue & Rejected \\
\hline H5 & Vertical differentiation & Rejected \\
\hline H6 & Horizontal differentiation & Not rejected \\
\hline H7 & Change time & Not rejected \\
\hline
\end{tabular}

\section{Conclusion}

The impacts of a new digital platform's market entry on incumbents are rarely considered in the literature. Our study adds a framework of impacts following a platform's market entry on incumbents and provides a detailed example using a large dataset. Additionally, we validate theories from the literature using time series analysis and structural breakage test.

The time series analysis showed changes after Uber's market entry. Within the study, the following hypotheses were not rejected. A platform's market entry causes a horizontal differentiation of the incumbents. The impact of a platform's market entry occurs with a time delay of more than one year. The following impacts were not verifiable. The winner-takes-it-all effect was not proven. Instead, the existing companies are focusing 


\section{When a New Platform Enters a Market, What Is the Impact on Incumbents?}

\section{Andreas J. Steur}

on a market niche. Hypotheses relating to declines in price, sales volume, and revenue as well as vertical differentiation were rejected.

The empirical results can be useful for companies that are afraid of a platform's market entry in their industry. For example, these companies can use the results of the changes identified for their strategic planning in order to react after a platform's market entry. For instance, the evidence about positive impacts after a platform's market entry can be useful for incumbents. Moreover, the established companies can profit from these results, which imply that there is a delay of at least one year.

Limitations include the practicable assumptions of the time series analysis and the structural breakage test. The calculated effects were tested in a city and within a business-to-customer context. In a business-to-business context, there could be higher market entry barriers and a greater need for technical know-how. As a result, scaling could further delay the impact in other areas and the extent of change may be different. For future research, we suggest an approach for predicting platform's tipping point to predict the timing of the changes after a platform's market entry. Furthermore, there is a need for research within industrial economics. More precisely, a game theoretical model for the competition between platforms and incumbents could be developed that takes into account multi-sidedness and the impact of network effects.

\section{Acknowledgements}

This article was developed from a paper presented at the ISPIM Innovation Conference in Stockholm, Sweden, June 17-20, 2018. ISPIM (ispim-innovation.com) the International Society for Professional Innovation Management - is a network of researchers, industrialists, consultants, and public bodies who share an interest in innovation management.

\section{About the Author}

Andreas J. Steur is Research Assistant at the Institute of Technology and Process Management (ITOP) at Ulm University, Germany. His research focuses on the management of digital platforms, particularly the competitive behaviour of digital platforms, which includes both competition between several digital platforms and competition between digital platforms and incumbents. Furthermore, his research examines the design of feedback mechanisms for digital platforms and approaches for scaling a platform.

\section{References}

Adner, R. 2017. Ecosystem as Structure. Journal of Management, 43(1): 39-58. https://doi.org/10.1177/0149206316678451

Andrews, D. W. K. 1993. Tests for Parameter Instability and Structural Change with Unknown Change Point. Econometrica, 61(4): 821-856.

https://www.jstor.org/stable/2951764

Armstrong, M. 2006. Competition in Two-Sided Markets. Journal of Economics, 37(3): 668-691.

https://doi.org/10.1111/j.1756-2171.2006.tb00037.x

Bai, J. 1994. Least Squares Estimation of a Shift in Linear Processes. Journal of Time Series Analysis, 15 (5): 453-472. https://doi.org/10.1111/j.1467-9892.1994.tb00204.x

Bertrand, J. 1883. Théorie Mathématique de la Richesse Social. Journal des Savants, 3(3): 499-508.

Brousseau, E., \& Penard, T. 2007. The Economics of Digital Business Models: A Framework for Analyzing the Economics of Platforms. Review of Network Economics, 6(2): 81-113.

https://doi.org/10.2202/1446-9022.1112

Caillaud, B., \& Jullien, B. 2003. Chicken \& Egg: Competition among Intermediation Service Providers. RAND Journal of Economics, 34(2): 309-328.

Choudary, S. P. 2015. Platform Scale. How an Emerging Business Model Helps Startups Build Large Empires with Minimum Investment. Platform Thinking Labs.

Chow, G. C. 1960. Tests of Equality Between Sets of Coefficients in Two Linear Regressions. Econometrica, 28(3): 591-605. https://www.jstor.org/stable/1910133

Eisenmann, T. R., Parker, G., \& Van Alstyne, M. W. 2006. Strategies for Two-Sided Markets. Harvard Business Review, 84(10): 92-101.

Evans, D., \& Schmalensee, R. 2007. The Industrial Organization of Markets with Two-Sided Platforms. Competition Policy International, 3(1): 151-179. 


\section{When a New Platform Enters a Market, What Is the Impact on Incumbents?}

\section{Andreas J. Steur}

Evans, D., \& Schmalensee, R. 2016. Matchmakers. The New Economics of Multisided Platforms. Boston, MA: Harvard Business Review Press.

Gawer, A., \& Cusumano, M. A. 2014. Industry Platforms and Ecosystems Innovation. Product Development \& Management Association, 31(3): 417-444. https://doi.org/10.1111/jpim.12105

Hackl, P. 2013. Einführung in die Ökonometrie (2nd Ed.). München: Pearson.

Hotelling. H. 1929. Stability in Competition. The Economic Journal, 39(153): 41-57. https://www.jstor.org/stable/2224214

Hotz, A., \& Fost, M. 2017. Die "Amazonisierung” des Konsums Game-Changer Amazon. In D. Schallmo, A. Rusnjak, J. Anzengruber, T. Werani, \& M. Jünger (Eds.), Digitale Transformation von Geschäftsmodellen: 669-696, Wiesbaden: Springer Fachmedien.

Muegge, S. 2011. Business Ecosystems as Institutions of Participation: A Systems Perspective on Community-Developed Platforms. Technology Innovation Management Review, 1(2): 4-13. http://doi.org/10.22215/timreview/495

Muegge, S. 2013. Platforms, Communities, and Business Ecosystems: Lessons Learned about Technology Entrepreneurship in an Interconnected World. Technology Innovation Management Review, 3(2): 5-15.

http://doi.org/10.22215/timreview/655

Oskam, J., \& Boswijk, A. 2016. Airbnb: the Future of Networked Hospitality Businesses. Journal of Tourism Futures, 2(1): 22-42. https://doi.org/10.1108/JTF-11-2015-0048

Parker, G., Van Alstyne, M. W., \& Choudary, S. P. 2016. Platform Revolution: How Networked Markets are Transforming the Economy and How to Make Them Work for You. New York: W. W. Norton \& Company.

Porter, M. E. 1998. Competitive Advantage: Creating and Sustaining Superior Performance. New York: Free Press.

Rochet, J. C., \& Tirole, J. 2003. Platform Competition in Two-Sided Markets. Journal of the European Economic Association, 1(4): 990-1029.

https://doi.org/10.1162/154247603322493212

Seamans, R., \& Zhu, F. 2010. Technology Shocks in Multi-Sided Markets: The Impact of Craigslist on Local Newspapers. Working Paper 10-11. New York: Net Institute.
Shy, O. 2010. Industrial Organization. Cambridge, MA: MIT Press.

Sun, M., \& Tse, E. 2007. When Does the Winner Take All in Two-Sided Markets? Review of Network Economics, 6(1): 16-40. https://doi.org/10.2202/1446-9022.1108

Täuscher, K., Hilbig, R., \& Abdelkafi, N. 2017. Geschäftsmodellelemente mehrseitiger Plattformen. In D. Schallmo, A. Rusnjak, J. Anzengruber, T. Werani, \& M. Jünger (Eds.), Digitale Transformation von Geschäftsmodellen: 179-211. Wiesbaden: Springer Fachmedien.

Tirole, J. 1999. Industrieökonomik (2nd Ed.). München: Oldenbourg.

Tiwana, A. 2014. Platform Ecosystems: Aligning Architecture, Governance, and Strategy. Waltham, MA: Morgan Kaufmann.

TLC. 2012. Newly Passed Fare and Lease Cap Rules. TLC Magazine, August 2012. Accessed June 1, 2017: http://www.tlcmag.com/archive/pre_2013_site/tlc_news_shell_aug12.html

TLC. 2017. Street Hail Livery. NYC Taxi \& Limousine Commission. Accessed October 1, 2017:

http://www.nyc.gov/html/tlc/html/industry/shl.shtml

Van Alstyne, M. W., Parker, G., \& Choudary, S. P. 2016. Pipelines, Platforms, and the New Rules of Strategy. Harvard Business Review, 94(4): 54-60.

Wallsten, S. 2015. The Competitive Effects of the Sharing Economy: How Is Uber Changing Taxis? Technology Policy Institute Studying the Global Information Economy, 2015(6): 1-21.

Zervas, G., Proserpio, D., \& Byers, J. W. 2017. The Rise of Sharing Economy: Estimating the Impact of Airbnb on the Hotel Industry. Journal of Marketing Research, 54(5): 687-705. https://doi.org/10.1509/jmr.15.0204

Citation: Steur, A. J. 2018. When a New Platform Enters a Market, What Is the Impact on Incumbents? Technology Innovation Management Review, 8(10): 44-53.

http://doi.org/10.22215/timreview/1192

Keywords: platforms, impact of market entry, incumbents, platform competition, two-sided market, multi-sided market 


\section{Academic Affiliations and Funding Acknowledgements}

Canadà
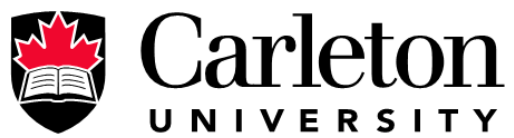

U N I V E R S I T Y

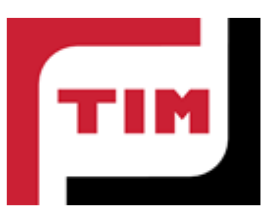

The Federal Economic Development Agency for Southern Ontario (FedDev Ontario; feddevontario.gc.ca) is part of the Innovation, Science and Economic Development portfolio and one of six regional development agencies, each of which helps to address key economic challenges by providing regionallytailored programs, services, knowledge and expertise.

- The TIM Review receives partial funding from FedDev Ontario's Investing in Regional Diversification initiative.

Technology Innovation Management (TIM; timprogram.ca) is an international master's level program at Carleton University in Ottawa, Canada. It leads to a Master of Applied Science (M.A.Sc.) degree, a Master of Engineering (M.Eng.) degree, or a Master of Entrepreneurship (M.Ent.) degree. The objective of this program is to train aspiring entrepreneurs on creating wealth at the early stages of company or opportunity lifecycles.

- The TIM Review is published in association with and receives partial funding from the TIM program. 